\title{
Mammography: Boon or Bane
}

\section{P D Gupta}

Former Director Grade Scientist Centre for Cellular and Molecular Biology, Hyderabad. India

*Corresponding Author: P D Gupta, Former Director Grade Scientist Centre for Cellular and Molecular Biology, Hyderabad. India.

E-Mail: pdg2000@hotmail.com

Received Date: November 05.2019; Accepted Date: December 05, 2019; Published Date: December 10,2019

Citation: P D Gupta. (2019) Mammography: Boon or Bane. J Women Health Care Issues, 2(2); Doi/10.31579/2642-9756/013

Copyright: C2019. P D Gupta, This is an open-access article distributed under the terms of the Creative Commons Attribution License, which permits unrestricted use, distribution, and reproduction in any medium, provided the original author and source are credited.
Abstract
With all advancements in drug discoveries and diagnostic technologies incidence of cancer rate should have come down, but it is not so. Between the years of 2010 to 2014, the breast cancer incidence rate was 124.9 per 100,000 women per year. Keywords: Mammography ; woman's health ;

\section{Introduction}

With all advancements in drug discoveries and diagnostic technologies incidence of cancer rate should have come down, but it is not so. Between the years of 2010 to 2014 , the breast cancer incidence rate was 124.9 per 100,000 women per year. The age-adjusted increase in breast cancer incidence rates during the 1990's was around 0.5\% per year. Furthermore, this rise was especially evident in women over the age of 50 . Breast cancer is the most frequently diagnosed cancer among women in 140 of 184 countries worldwide. Globally, breast cancer now represents one in four of all cancers in women. Although breast cancer is thought to be a disease of the developed world, almost $50 \%$ of breast cancer cases and $58 \%$ of deaths occur in less developed countries (GLOBOCAN 2008). Incidence rates vary greatly worldwide from 19.3 per 100,000 women in Eastern Africa to 89.7 per 100,000 women in Western Europe. [1]

The age old breast cancer screening technique, mammography, is still good, though new techniques such as thermogrphy cannot match with Mammography. Studies suggest that a mammogram is more likely to produce an accurate result than thermography. Thermography is a test that uses an infrared camera to detect heat patterns and blood flow in body tissues. Digital infrared thermal imaging (DITI) is the type of thermography that's used to diagnose breast cancer. DITI reveals temperature differences on the surface of the breasts to diagnose breast cancer [2]. A mammogram is an X-ray image of your breasts used to screen for breast cancer. Mammograms play a key role in early breast cancer detection and help decrease breast cancer deaths. [3] Breast tissue is composed of milk glands, milk ducts and supportive tissue (dense breast tissue), and fatty tissue (non dense breast tissue) [4]. When viewed on a mammogram, women with dense breasts have more dense tissue than fatty tissue. The levels of breast density depend on the dence tissue present in the breast and are clearly demarcated in mammograph in the following 4 types:
A: Almost entirely fatty indicates that the breasts are almost entirely composed of fat. About 1 in 10 women has this result B: Scattered areas of fibroglandular density indicates there are some scattered areas of density, but the majority of the breast tissue is nondense. About 4 in 10 women have this result.

C: Heterogeneously dense indicates that there are some areas of nondense tissue, but that the majority of the breast tissue is dense. About 4 in 10 women have this result.

D: Extremely dense indicates that nearly all of the breast tissue is dense. About 1 in 10 women has this result.

\section{Mammography affects Woman's health both ways}

Mammograms are used as a screening tool to detect early breast cancer in women experiencing no symptoms. They can also be used to detect and diagnose breast disease in women experiencing symptoms such as a lump, pain, skin dimpling or nipple discharge A mammogram is an x-ray picture of the breast. It can be used to check for breast cancer in women who have no signs or symptoms of the disease. It can also be used if you have a lump or other sign of breast cancer. Screening mammography is the type of mammogram that checks you when you have no symptoms. Everyone experiences mammograms differently. Some women may feel pain during the procedure, and others may not feel anything at all. Most women feel some discomfort during the actual X-ray process. The pressure against your breasts from the testing equipment can cause pain or discomfort, and that's normal, In general, regular mammograms are not recommended for women who are at average risk for breast cancer if they are under 40 years old, in part, because breast tissue tends to be more dense in young women, making mammograms less effective as a screening too Radiation from Mammography May Increase Risk of Breast Cancer. In addition, women who are exposed to radiation for other purposes or women who are carriers of the BRCA (breast cancer susceptibility) gene are at an even higher risk of experiencing adverse effects 
from mammography radiation [5]

Screening mammograms are the international gold standard for detecting breast cancer early. Mammograms can usually find lumps 2 or 3 years before a woman or her health care provider can feel them. Myth: Radiation exposure during a mammogram can cause cancer

Many women begin mammograms at age 40 and have them every one to two years. The American Cancer Society advises women with an average risk to begin screening mammograms yearly at age 45 until age 54, and then continue every two years for at least the next 10 years. This routine continues until they turn about 75 years of age or if, for whatever reason, they have limited life expectancy.

Each year, millions of women undergo mammograms for early detection of possible breast cancer. It's an unpleasant procedure that uses X-rays. Researchers at TU Eindhoven are working on a 'breast-friendly' method, without radiation, that is more accurate and generates $3 \mathrm{D}$ rather than $2 \mathrm{D}$ images. New data document that for a woman beginning annual mammographic screening at age 50 and continuing until age 75 , the benefit exceeds the radiation risk by a factor of almost 100 . Even for a woman who begins annual screening at age 35 and continues until age 75 , the benefit of reduced mortality is projected to exceed the radiation risk by a factor of more than 25. [6]

In the regular screening method the breast is squeezed tight between two plates in order to produce one or more good X-ray photos. Apart from being unpleasant, it is not without risk. The X-rays used can themselves be a contributor to the onset of cancer. Moreover, it is often unclear whether the anomaly found is malignant lesion or not. More than twothirds of the cases where something worrying can be seen on the X-ray photos is a false-positive: after biopsies, they are not found to be cancer This is why science is seeking alternatives.

Researchers at TU Eindhoven have now cleared a major scientific hurdle towards a new technology in which the patient lies on a table and the breast hangs freely in a bowl. Using special echography (inaudible sound waves) a 3D image is made of the breast. Any cancer is clearly identifiable on the generated images; the researchers therefore expect there to be many fewer false-positive results.

The new technology builds on the patient-friendly prostate cancer detection method developed at TU/e whereby the doctor injects the patient with harmless microbubbles. An echoscanner allows these bubbles to be precisely monitored as they flow through the blood vessels of the prostate. Since cancer growth is associated with the formation of chaotic microvessels, the presence and location of cancer become visible. This method works well for the prostate and this is now being widely tested in hospitals in the Netherlands, China and, soon, Germany. For breast cancer the method had not yet been suitable because the breast shows excessive movement and size for accurate imaging by standard echography.

Researchers Libertario Demi, Ruud van Sloun and Massimo Mischi have now developed a variant of the echography method that is suitable for breast investigation. The method is known as Dynamic Contrast Specific Ultrasound Tomography. Echography with microbubbles uses the fact that the bubbles will vibrate in the blood at the same frequency as the sound produced by the echoscanner, as well as at twice that frequency; the socalled second harmonic. By capturing the vibration, you know where the bubbles are located. But body tissue also generates harmonics, and that disturbs the observation.

For the new method the researchers are using a phenomenon that Mischi happened upon by chance and later investigated its properties together with Demi. They saw that the second harmonic was a little delayed by the gas bubbles. The researchers have now developed a new visualization method. The more bubbles are encountered by the sound on its route, the bigger the delay compared to the original sound. By measuring this delay, the researchers can thus localize the air bubbles and do so without any disturbance because the harmonic generated by the body tissue is not delayed, and is therefore discernible. This difference, however, can only be seen if the sound is captured on the other side. So this method is perfectly suited to organs that can be approached from two sides, like the breast.

The researchers are currently putting together an international, strong medical team to start performing preclinical studies. Moreover, he forecasts that the technology that has been developed will probably not operate on a standalone basis but in combination with other methods, which will create a better visualization. One of the candidates for this elastography, a variant of echography whereby the difference in the rigidity of the tumor and healthy tissue can be used to detect cancer.

\section{New Guide lines for mammography}

Current mammography standards were set by the FDA in 1992 with the Mammography Quality Standards Act. Proposed Changes to the Quality Standards Act

The most notable changes to the act involve patient education, results categorization and increased agency power. Let's take a closer look at each:

Patient Education - New standards would require facilities to provide women with information about breast density and how it can affect the accuracy of mammography. The FDA would like to expand the categories used to describe findings. The current categories include: negative, benign, probably benign, suspicious, highly suggestive of malignancy and incomplete. The agency would like to add the categories "known biopsy proven malignancy" and "post procedure mammograms for marker placement."In addition, the proposed changes would modernize the technological aspects of the standards which include the use of 3D imaging technology which allows technicians to take pictures of multiple slices of the breast and join them together to get a more complete picture of the breast tissue. It is believed that 3D imaging will allow doctors to find smaller tumors and better understand their placement within the breast. 


\section{References}

1. Ferlay J, Shin HR, Bray F, Forman D, Mathers C. (2008) Parkin DM 2010 Estimates of worldwide burden of cancer in Int J Cancer. 127(12):2893-2917

2. "Breast Cancer Screening: Thermogram No Substitute for Mammogram". Fda.gov. US Food and Drug Administration. 27 October 2017. Archived from the original on 23 June 2018. Retrieved 23 June 2018.

3. Ballal H S and Gupta P D. (2013) Peeping Inside the Body. Capricon Publishers, Jaipur, India

4. Gupta, P D and Iino, A. (2000) Mothering A Cause. Oxford and IBH Publishers, New Delhi, India

5. Mettler F A., Upton A C. Kelsey C A. Ashby R N. Rosenberg R D. Linver, M N. (1996) Benefits versus risks from mammography: A critical reasessment Cancer, 77,(5) 903-909.
6. Izumo T, Sasada S, Chavez C, Matsumoto Y, Tsuchida T. (2014) Endobronchial Ultrasound Elastography in the Diagnosis of Mediastinal and Hilar Lymph Nodes . Jap J ClinOncol, 44,( 10), 956-962,

7. Demi M., Prediletto R., Soldati G., Demi L. (2019) Physical mechanisms providing clinical information from ultrasound lung images: hypotheses and early confirmations, IEEE Trans Ultrasonics Ferroelectrics and Frequency Control,

8. Schalk SG, Postema A, Saidov, Demi TA Smeenge L, M, de la Rosette JJ. (2016) 3D surface-based registration of ultrasound and histology in prostate cancer imaging. Computerized Medical Imaging and Graphics 47, 29-39

9. https://www.breastcancer.org > asbrs-issues-updated-screeningguideline 